\title{
FAKTOR-FAKTOR YANG MEMPENGARUHI PADA SISWA SMP MOTIVASI BERIBADAH NEGERI 1 NGEMPLAK SLEMAN)
}

\author{
Mujiana \\ Program Pasca Sarjana \\ Universitas Muhammadiyah Yogyakarta \\ E-mail: mujianacakran@ymail.com
}

\begin{abstract}
Abstrak
Tujuan penelitian ini adalah mengetahui pelaksanaan ibadah siswa, tingkat motivasi beribadah dan faktor yang mempengaruhi motivasi beribadah. Metode penelitian ini yaitu pendekatan kualitatif deskriptif dan bertempat di SMP Negeri 1 Ngemplak. Waktu penelitian pada bulan April-Juni 2018 dengan siswa kelas VIII sebagai sampel penelitian. Teknik pengumpulan data menggunakan angket, wawancara dan observasi. Sedangkan analisis data menggunakan reduksi data, display dan verifikasi data atau kesimpulan. Hasil dari penelitian ini 1) Pelaksanaan ibadah di SMP Negeri 1 Ngemplak meliputi a) ibadah shalat termasuk kategori Baik $(77,31 \%)$ yang terdiri shalat lima waktu $(85,42)$, shalat jama'ah $(74,31)$, shalat sunah dhuha $(72,22)$, b) ibadah doa termasuk kategori sangat baik $(87,50 \%)$, c) ibadah puasa termasuk kategor Baik $(71,50 \%)$ yang terdiri dari puasa ramadhan $(80,56)$, puasa sunah $(59,72)$ dan shalat tarawih $(73,61)$ serta ibadah membaca alQur'an termasuk kategori Baik $(76,00)$ yang terdiri membaca setiap hari $(70,14)$, khatmil qur'an $(81,48)$ dan kemampuan membaca dengan muratal $(76,39)$. Sedangkan secara keseluruhan pelaksanaan ibadah shalat siswa termasuk kategori 'Baik' $(78,03 \%)$. 3) Faktor yang mempengaruhi motivasi beribadah siswa adalah unsur instrinsik dan ekstrinsik.
\end{abstract}

Kata kunci: faktor-faktor, motivasi beribadah, siswa SMP

\begin{abstract}
The purpose of this study was to determine the implementation of student worship, the level of motivation to worship and factors that influence motivation to worship. The method of this research is a descriptive qualitative approach and is located at SMP Negeri 1 Ngemplak. The time of research in April-June 2018 with students of class VIII as research samples. Data collection techniques using questionnaires, interviews and observations. Whereas data analysis uses data reduction, display and data verification or conclusions. The results of this study 1) The implementation of worship in SMP Negeri 1 Ngemplak includes a) prayer services including the Good category (77.31\%) which consists of five time prayers (85.42), congregational prayers (74.31), sunnah prayer duha (72.22), b) prayer services are in the very good category $(87.50 \%), c)$ fasting is included in the Good category (71.50\%) consisting of Ramadan fasting (80,56), sunnah fasting $(59,72)$ and tarawih prayer $(73.61)$ as well as the worship of reading the Koran, including the Good category (76.00) which consists of reading every day (70.14), khatmil qur'an (81.48) and reading skills with muratal $(76,39)$. While overall the implementation of student prayer services included in the category of 'Good' (78.03\%). 3) Factors that influence students' motivation to worship are intrinsic and extrinsic elements.
\end{abstract}

Keywords: factors, motivation to worship, junior high school students

\section{Info Artikel}

Diterima Agustus 2019, disetujui September 2019, diterbitkan Desember 2019 


\section{PENDAHULUAN}

Pendidikan memegang peranan penting dalam mencapai kesempurnaan manusia dari sisi ilmu pengetahuan maupun sisi ketaatan beribadah sehingga derajat takwa kepada Allah dapat terealisir, kondisi tersebut sangat diharapkan sebagai salah satu tujuan pembelajaran di sekolah dan salah satu indicator keberhasilan adalah siswa rajin melaksanakan shalat wajib. Untuk itu guru perlu membangkitkan motivasi siswa agar mereka mampu mengaktualisasikan dirinya ke ranah yang positif.

Motivasi memliki beberapa peran dalam kehidupan manusia, setidaknya ada empat peran motivasi yaitu pertama, motivasi berfungsi sebagai pendorong manusia dalam berbuat sesuatu, sehingga menjadi unsur penting dan tingkah laku atau tindakan manusia. Kedua, motivasi berfungsi untuk menetukan arah dan tujuan. Ketiga, motivasi berperan sebagai penyeleksi atas perbuatan yang akan dilakukan oleh manusia baik atau buruk sehingga tindakannya selektif. Empat, motivasi berfungsi sebagai penguji sikap manusia dalam beramal, benar atau salah sehingga bisa dilihat kebenaran atau kesalahannya.

Dengan demikian dapat disimpulkan bahwa motivasi berfungsi sebagai pendorong, penentu, penyeleksi dan penguji sikap manusia dalam kehidupannya. Oleh karena itu, orang yang memiliki motivasi beribadah, ia akan berusaha menjaga dan melestarikan lingkungan dan bagaimana memperlakukan hewan sesuai haknya sebagai makhluk ciptaan-Nya dengan tujuan untuk beribadah kepada Allah SWT.

Motivasi beribadah timbul bukan karena dorongan alami/asasi, melainkan dorongan yang tercipta karena tuntutan perilaku. Menurut Freud, kerataan beribadah seseorang timbul karena reaksi manusia atas ketakutannya sendiri. Lebih lanjut ia menegaskan bahwa orang mempunyai sikap ketaatan beribadah semata-mata karena didorong oleh keinginan untuk menghindari keadaan yang berbahaya yang akan menimpanya dan memberi rasa aman bagi dirinya sendiri.

Motivasi beribadah berkembang bukan secara langsung sebagai faktor bawaan yang diwariskan secara turun temurun, akan tetapi terbentuk dari berbagai unsur kejiwaan (afektif, kognitif, dan konatif). Thouless mengemukakan empat faktor yang mempengaruhi perkembangan motivasi beribadah yaitu:

a. Pengaruh pendidikan/pengajaran dan berbagai tekanan sosial, termasuk di dalamnya pendidikan dari orang tua, tradisi -tradisi sosial, tekanan lingkungan sosial yang disepakati oleh lingkungan itu (faktor sosial).

b. Berbagai pengalaman yang membantuk sikap keagamaan terutama pengalamanpengalaman mengenai keindahan, keselarasan dan kebaikan di dunia lain (faktor alami), konflik moral (faktor moral) dan faktor pengalaman emosional atau afektif

c. Faktor-faktor yang seluruhnya timbul atau sebagian timbul dari kebutuhan yang tidak terpenuhi, terutama kebutuhan terhadap keamanan, cinta kasih, harga diri, dan ancaman kematian.

d. Berbagai proses pemikiran verbal (faktor intelektual).

\section{METODE PENELITIAN}

Metode penelitian ini menggunakan pendekatan kualitatif deskriptif dan penelitian ini bertempat di SMP Negeri 1 Ngemplak. Waktu penelitian dilaksanakan pada bulan April-Juni 2018 dengan melibatkan siswa kelas VIII sebagai sampel penelitian. Teknik pengumpulan data menggunakan angket, wawancara dan observasi. Sedangkan analisis data menggunakan reduksi data, display dan verifikasi data atau kesimpulan. 


\section{HASIL PENELITIAN DAN PEMBAHASAN \\ Pelaksanaan Ibadah}

Islam sangat istimewa hingga menjadikan seluruh kegiatan manusia sebagai ibadah apabila diniatkan dengan ikhlas karena Allah demi mencapai keridhan-Nya serta dikerjakan menurut cara-cara yang disyariatkan oleh-Nya. Islam tidak memandang ruang lingkup ibadah pada sudut-sudut tertentu saja. Seluruh kehidupan manusia adalah medan amal dan persendian bekal bagi umat Islam sebelum kembali menghadap Allah swt. Dalam penelitian ini, peneliti fokus terhadap ibadah shalat, puasa dan membaca alQur'an.

\section{Ibadah Shalat}

Menurut bahasa arab, shalat berarti doa. Kemudian secara istilah yaitu ibadah yang tersusun dari beberapa perkataan dan beberapa perbuatan yang dimulai dengan takbir disudahi dengan shalatm dan memenuhi beberapa syarat yang ditentukan. Dan shalat adalah tangga bagi orang-orang beriman dan tempat untuk berkomunikasi kepada Allah, tiada perantara dalam shalat antara hambanya yang mukmin dengan Tuhannya. Dengan shalat akan tampak bekas kecintaan seorang hamba dengan tuhannya, karena tidak ada yang lebih menyenangkan bagi orang (mukmin) yang mencintain melainkan berkhalwat kepada zat yang dicintainnya, untuk mendapatkan apa yang dimintanya.

Dari pembahasan mengenai pelaksanaan ibadah shalat siswa SMP Negeri 1 Ngempak secara keseluruhan termasuk katergori 'Baik' (77,31\%). Hal ini dapat diperhatikan seperti table berikut ini:

Tabel 1.

Kategori Pelaksanaan Ibadah Shalat

\begin{tabular}{|c|l|c|c|c|c|}
\hline No & \multicolumn{1}{|c|}{ Shalat } & Jumlah & Persentase & Rata-Rata & Kategori \\
\cline { 1 - 4 } 1 & Wajib & 123 & 85.42 & & \multirow{2}{*}{77.31} \\
\cline { 1 - 4 } 2 & Berjama'ah & 107 & 74.31 & & \\
\cline { 1 - 4 } 3 & Sunah & 104 & 72.22 & & \\
\hline
\end{tabular}

\section{Ibadah Doa dan Dzikir}

Secara bahasa do'a berasal dari bahasa Arab, al-du'a, da'a-yad'u, du'a anwa da'watan yang artinya memanggil, mengundang, mengajak, meminta, atau memohon. Doa merupakan sarana memohon kepada Allah sehingga manusia menjadi lebih dekat kepada-Nya. Allah memerintahkan manusia untuk memohon kepada-Nya dan membenci manusia yang menyombongkan diri. Doa adalah suatu permohonan, suatu cara untuk membawa keinginan, masalah dan kebutuhan seseorang ke hadapan Allah.

Secara kesimpulan pelaksanaan ibadah doa siswa SMP Negeri 1 Ngemplak Sleman termasuk kategori 'Sangat Baik' (87,50\%). Hal ini menunjukan bahwa sebagian besar siswa SMPN Ngemplak ketika memulai ber aktifitas selalu ingat kepada Allah yang diwujudkan dalam lafal atau ucapan do a dan dzikir. 


\section{Ibadah Puasa}

Kata puasa shiyam bentuk merupakan shaum dan mashdar yang artinya menurut bahasa ialah menahan. Sedangkan menurut syara' ialah menahan dari perkara yang membatalkan puasa dengan niat tertentu pada seluruh hari yang dapat dibuat berpuasa. Puasa menurut bahasa adalah menahan diri dari seegala sesuatu. Sedangkan menurut istilah adalah menahan diri dari segala yang membatalkan mulai terbitnya fajar hingga tenggelamnya matahari. Sehingga dapat diambil kesimpulan bahwa puasa ialah menahan diri dari segala perkara yang membatalkan puasa dari mulai terbitnya fajar sampai dengan terbenamnya matahari.

Puasa merupakan pendidikan dan pelurusan jiwa dan penyembuh bagi berbagai penyakit jiwa dalam tubuh. Hal ini dikarenakan pencegahan dari makan dan minum, sejak sebelum fajar hingga terbenamnya matahari pada semua hari bulan ramadhan, merupakan latihan bagi manusia dalam melawan dan menundukkan hawa nafsunya. Secara kesimpulan pelaksaan ibadah puasa siswa SMP Ngeri 1 Ngempak termasuk kategori 'Baik' (71,30\%). Hal ini seperti terlihat dalam tabel berikut ini:

Tabel 2.

Kategori Pelaksanaan Ibadah Puasa

\begin{tabular}{|c|l|c|c|c|c|}
\hline No & \multicolumn{1}{|c|}{ Ibadah } & Jumlah & Persentase & Rata-rata & Kategori \\
\hline 1 & Ramadhan & 116 & 80.56 & & \\
\cline { 1 - 4 } 2 & Sunah & 86 & 59.72 & \multirow{2}{*}{71.30} & Baik \\
\cline { 1 - 4 } 3 & Tarawih & 106 & 73.61 & & \\
\hline
\end{tabular}

\section{Ibadah Membaca al-Qur'an}

Al-Qur'an artinya bacaan. Al-Qur'an juga diartikan sebagai bacaan yang maha sempurna dan mulia. Kemulian dan kesempurnaan al-Qur'an tidak hanya dirasakan oleh ahli tafsir, namun masyarakat awampun bisa merasakannya. Al-Qur'an adalah kitab yang berisi bimbingan bagi siapa saja yang bertakwa kepada Allah dan menghindari kejahatan. Selain itu, al-Qur'an juga memberikan prinsip dasar yang dapat dijadikan pegangan untuk mencapai keberhasilan dan kesejahteraan baik lahir maupun batin. AlQur'an juga memberikan peneguhan agar manusia memiliki kepercayaan diri yang sejati dan mampu memberikan motivasi yang kuat dan prinsip yang teguh.

Mengenai pembahasan pelaksanaan ibadah membaca al-Qur'an dapat disimpulkan bahwa pelaksaan membaca al-Qur'an di SMP Negeri 1 Ngemplak dapat dikategorikan 'Baik' (76,00\%). Hal ini diperkuat dengan hasil tabel berikut ini: 
Tabel 3.

Kategori Pelaksanaan Ibadah Membaca Al-Qur'an

\begin{tabular}{|c|l|c|c|c|c|}
\hline No & \multicolumn{1}{|c|}{ Ibadah } & Jumlah & Persentase & Rata-rata & Kategori \\
\hline 1 & Membaca & 101 & 70.14 & \multirow{2}{*}{76.00} & \multirow{2}{*}{ Baik } \\
\cline { 1 - 4 } 2 & Khataman & 88 & 81.48 & & \\
\cline { 1 - 4 } 3 & Muratal & 55 & 76.39 & & \\
\hline
\end{tabular}

Dari pembahasan mengenai pelaksanan ibadah siswa yang meliputi ibadah shalat, doa, puasa dan tadarus al-Qur' an di SMP Negeri 1 Ngemplak dapat disimpulkan dalam kategori 'Baik' (78,03\%). Seperti terlihat dalam tabel berikut ini,

Tabel 4.

\section{Kategori Pelaksanaan Semua Ibadah}

\begin{tabular}{|c|l|c|c|c|}
\hline No & \multicolumn{1}{|c|}{ Ibadah } & Jumlah & Rata-rata & Kategori \\
\hline 1 & Shalat & 77.31 & & \\
\cline { 1 - 2 } 2 & Doa & 87.50 & \multirow{2}{*}{78.03} & Baik \\
\cline { 1 - 3 } 3 & Puasa & 71.30 & & \\
\cline { 1 - 3 } 4 & Tadarus al-Qur'an & 76.00 & & \\
\hline
\end{tabular}

\section{Tingkat Motivasi Beribadah}

Ketaatan orang beragama, dilihat berdasarkan kualitas dan kuantitas ibadahnya. Kualitas ibadah sering ditandai dengan niat yang tulus ikhlas. Ketika seseorang niat melakukan ibadah, maka ia sudah mendapatkan satu pahala, dan jika ia merealisasikan ibadah itu, maka ia akan mendapat sepuluh pahala. Sebaliknya, jika ia berniat melakukan kejahatan, ia tidak melakukannya maka ia tidak mendapat dosa, tapi jika ia melakukan kejahatan itu maka ia mendapat satu dosa

Menurut tingkatannya, motivasi ibadah dilihat dari keikhlasannya dibedakan menjadi 3 (tiga), yaitu: Pertama, motivasi karena memandang ibadah sebagai suatu kewajiban yang harus ditunaikan. Bagi orang yang memandang ibadah sebagai kewajiban, sikap yang muncul adalah nrimo ing pandhum, pantang menolak, dan tidak ada keinginan atau angan-angan untuk mengingkarinya. Kedua, Adakalanya orang melakukan ibadah karena didorong oleh keinginan untuk memperoleh pahala atau imbalan dari Allah SWT. Ibadah jenis ini disebut 'ibadah lil-matsubah, "ibadah karena upah/pahala". Ketiga, motivasi yang lebih tinggi mutunya, yaitu ibadah karena sematamata untuk mendekatkan diri kepada Allah, memperoleh ridho Allah, atau ingin agar hubungannya dengan Allah bertambah dekat.

Dari pembahasan mengenai motivasi beribadah SMP Negeri 1 Ngemplak dapat disimpulkan bahwa tingkat motivasi beribadah siswa termasuk kategori 'Tinggi' $(83,85 \%)$. Hal ni dapat dilihat dalam tabel berikut ini, 
Tabel 5.

Kategori Pelaksanaan Ibadah Membaca Al-Qur'an

\begin{tabular}{|c|l|c|c|c|c|}
\hline No & \multicolumn{1}{|c|}{ Motivasi } & Jumlah & Persentase & Rata-rata & Kategori \\
\hline 1 & Kesadaran & 103 & 71.53 & & \\
\cline { 1 - 4 } 2 & Ketenangan & 127 & 88.19 & \multirow{2}{*}{83.85} & \multirow{2}{*}{ Tinggi } \\
\cline { 1 - 4 } 3 & Kesehatan & 129 & 89.58 & & \\
\hline 4 & Kecerdasan & 124 & 86.11 & & \\
\hline
\end{tabular}

\section{Factor yang Mempengaruhi Ketaatan Siswa}

Dalam melakukan sebuah aktivitas seseorang tidak lepas dari dua factor, yaitu intrinsic dan ekstrinsik. Berdasarkan pembahasan mengenai faktor yang mempengaruhi motivasi beribadah SMP Negeri 1 Ngemplak dapat disimpulkan bahwa tingkat motivasi beribadah siswa termasuk kategori 'Tinggi' (69,97\%), sedangkan 30,03\% dipengaruhi dari faktor lainnya. Hal ini dapat dilihat dalam tabel berikut ini.

Tabel 6.

Kategori Ketaatan Siswa

\begin{tabular}{|c|l|c|c|c|}
\hline No & \multicolumn{1}{|c|}{ Faktor Pengaruh } & Jumlah & Presentase & Rata-Rata \\
\hline 1 & Orang Tua & 97 & 67,36 & \multirow{2}{*}{6} \\
\cline { 1 - 3 } 2 & Guru & 129 & 89,58 & \multirow{2}{*}{69,97} \\
\hline 3 & Teman Sebaya & 83 & 57,64 & \\
\hline 4 & Lingkungan & 94 & 65,28 & \\
\hline
\end{tabular}

Berdasarkan table di atas, dapat diperhatikan bahwa pengaruh guru lebih besar dibandingkan dengan orang tua. Hal ini setelah peneliti melakukan pengamatan lebih jauh karena guru memiliki penekanan lebih besar ketika di sekolah dibandingkan orang tua ketika di rumah. Selain itu, banyak sekali orang tua yang belum melakukan ibadah secara rutin atau kontinu. Dalam hal shalat misalnya, banyak orang tua yang belum melakukan sholat secara rutin alias masih banyak yang bolong-bolong.

\section{KESIMPULAN}

Dari hasil kajian yang telah dilakukan oleh peneliti, maka penelitian ini menyimpulkan sebagai berikut:

1. Pelaksanaan ibadah di SMP Negeri 1 Ngemplak meliputi a) ibadah shalat termasuk kategori Baik $(77,31 \%)$ yang terdiri shalat lima waktu $(85,42)$, shalat jama'ah $(74,31)$, shalat sunah dhuha $(72,22)$, b) ibadah doa termasuk kategori sangat baik $(87,50 \%)$, c) ibadah puasa termasuk kategor Baik $(71,50 \%)$ yang terdiri dari puasa ramadhan $(80,56)$, puasa sunah $(59,72)$ dan shalat tarawih $(73,61)$ serta ibadah 
membaca al-Qur'an termasuk kategori Baik $(76,00)$ yang terdiri membaca setiap hari $(70,14)$, khatmil qur'an $(81,48)$ dan kemampuan membaca dengan muratal $(76,39)$. Sedangkan secara keseluruhan pelaksanaan ibadah shalat siswa termasuk kategori 'Baik' (78,03\%).

2. Tingkat motivasi beribadah siswa meliputi mengerjakan ibadah atas kemauan sendiri (71,53), motivasi shalat memberikan ketenangan jiwa $(88,19)$, keyakinan bahwa puasa menyehatkan tubuh $(89,58)$ dan keyakinan dengan banyak membaca al-Qur'an akan meningkatkan kecerdasan otak $(86,11)$. Sehingga secara kesimpulan tingkat motivasi siswa dalam melaksanakan ibadah termasuk kategori 'Tinggi' $(83,85 \%)$.

3. Factor yang mempengaruhi motivasi ibadah siswa adalah instriksik dan ekstrinsik. Untuk factor instrinsik sebesar 30,03\% (tidak tinggi), sedangkan ekstrinsik sebesar $69,97 \%$ (cukup tinggi) yang meliputi a) orang tua sebesar $67,36 \%$ artinya cukup tinggi, b) guru sebesar $89,58 \%$ artinya sangat tinggi, c) teman sebaya sebesar $57,64 \%$ artinya tidak tinggi dan d) lingkungan masyarakat sebesar 65,28\% artinya cukup tinggi. Sehingga dapat disimpulkan bahwa faktor yang mempengaruhi motivasi beribadah dipengaruhi oleh factor instrinsik $(30,03 \%)$ dan ekstrinsik. $69,97 \%$.

\section{DAFTAR PUSTAKA}

Al-Muqaddam Ahmad Ismail, Mengapa harus Shalat, Jakarta: Amzah, 2007

Amar Abu Imron, Fat-Hul Qarib Jilid 1, Kudus: Menara Kudus, 1982

Fazlur Rahman, Islam, penerjemah Ahsin Mohammad, Bandung: Pustaka, 2000

Mahmud Sani, Fiqih. Surabaya: CV. MIA, 2008

Mohammad Usman Najati, Al-Qur'an dan Ilmu Jiwa, Bandung: Pustaka, 2004

Ramayulis, Psikologi Agama, Jakarta: Kalam Mulia, 2013

Sufyan Sauri, Membangun ESQ dengan Doa, Bandung: Media Hidayah Publisher, 2006

Sulaiman Rasyid, Fiqih Islam, Bandung: CV Sinar Baru, 1980

Tohari Musnamar, Dasar-Dasar Konseptual Bimbingan dan Konseling Islam, Yogyakarta: UII Press, 1992 